\title{
DO ATO DE ENSINAR NUMA SOCIEDADE ADMINISTRADA
}

\author{
Newton Ramos-De-Oliveira*
}

\begin{abstract}
RESUMO: Este artigo utiliza conceitos da Teoria Crítica para analisar o ensino como ato formativo. Há um jogo de forças em contínua tensão que caracteriza esta ação humana fundamental em que se destaca a necessidade de, ao mesmo tempo, preservar e modificar. O quadro se torna mais complexo quando inserido na atual sociedade administrada, saturada de informaçōes profusas, fragmentadas e desconexas. Eis o solo em que viceja a Indústria Cultural e um de seus produtos, a semiformação. Este conjunto de reflexōes se impõe a qualquer escola que se pretenda crítica.
\end{abstract}

Palavras-chave: Indústria Cultural, Educação, Ensino, Sociedade Administrada, Razão Instrumental.

Como podemos facilmente imaginar e como farta documentação histórica demonstra, o ato de ensinar nunca deve ter sido simples. Quando a humanidade sentiu a necessidade de formar as novas gerações, inserindoas no mundo que estava sendo construído pelo trabalho e pela linguagem, a imitação direta da cotidianidade adulta pelos jovens foi sendo substituída pela instrução, pela transmissão consciente de ensinamentos. A escrita cumpriu, então, desde essas primeiras épocas, papel crescentemente fundamental ao lado da palavra falada. E nesse novo ambiente, a escola, um impasse se instala: como preservar o que estava construído com a necessidade de prosseguir modificando? Como combinar num mesmo ato a adaptação e a superação? Como conciliar um ato que se destinava a preservar as conquistas dos homens com a criatividade e flexibilidade que permitissem aos jovens abandonar o caminho adulto das certezas e dos resultados obtidos em busca de novas conquistas, novas construções, novos bens culturais? Ou seja, como harmonizar a conformidade com o anticonformismo? O conhe-

* Pesquisador/CNPq, co-responsável pelo Grupo de Pesquisa "O Potencial Pedagógico da Teoria Crítica" (UFSCar/Unimep).E-mail:ramosoli@nutecnet.com.br 
cimento com sua negação, o aceito com o rejeitado, o conquistado com sua transcendência?

Não foi um caminho fácil. As civilizaçôes que melhor conseguiram equilibrar essas duas direções opostas alcançaram estágios superiores. Mas, mesmo assim, não sem sobressaltos, recuos, opressões. Veja-se a Grécia Clássica (Ramos-de-Oliveira, 1998), por exemplo. O julgamento e condenação de Sócrates passam a simbolizar a dificuldade de conciliar tensões. Cada época trará novos conteúdos e novos contornos a esta dificuldade que caracteriza o ensino, a educação, a formação do ser humano e de sua sociedade. A Igreja toda poderosa na Idade Média, o conflito entre seitas do cristianismo após a Reforma, o aparecimento do absolutismo no século XVII, o totalitarismo que dominou povos e territórios no século que se acaba - são alguns exemplos das prisões que cercaram o ato de ensinar através dos tempos. Mas nenhum regime teve a permanência e a força do capital. O capital, puro ou como mercadoria e mercado, tem moldado, constituído e integrado o ensino, às vezes com estardalhaço e outras, as ocasiōes talvez mais perigosas, subterraneamente, imperceptivelmente. Exerce um encanto e uma sedução que tudo invade.

Para examinar este ato complexo, é necessário ver alguns aspectos de frente e outros de verso, num movimento que se estenda do micro ao macro. A polaridade universal-particular tem que ser percorrida nos dois sentidos se quisermos apreender a realidade. A justificativa para tal conceito que conjuga perspectivas pode ser encontrada em Marx, quando este define que "o concreto é a soma das múltiplas determinações do ser" e quando, por outro lado, afirma (com Engels) em rodapé na Ideologia Alemã que só há uma ciência: a História. O horizonte epistemológico que corresponde ao pensamento marxiano deve ser a busca do concreto-histórico, ou seja, de determinação do ser de cima para baixo (macroestrutural) e de baixo para cima (microfísico). Algumas abordagens buscam enriquecer o jogo do histórico e da concretude. O que faz Theodor W. Adorno em Minima Moralia a não ser entremear e entrelaçar o universal no particular e viceversa? O que faz Marx em $O$ dezoito brumário de Luis Bonaparte? Sartre via a práxis como resultante de movimentos concretos existenciais, distinguindo a ação dos grupos como exercidas "em serialidade", na qual os membros não tinham ligação orgânica, e grupos "em fusão", quando extremamente articulados numa só práxis. Em Questão de método conjuga tais perspectivas num método que extrai de Henri Lefebvre e que alia dimensões horizontais e verticais, ou históricas. Em sua obra monumental $O$ idiota da família, Sartre acompanha a história a partir do cotidiano de Charles Baudelaire, 
contrapondo e decifrando este cotidiano a partir do esclarecimento histórico. Costura, portanto, o micro e o macro num movimento só.

Não é propósito deste texto dar conta desta integralidade complexa, mas apenas indicar a dificuldade de, a pretexto de ser pedagógico, simplificar tanto a realidade complexa que acabemos eliminando a complexidade, até que, nesse mesmo movimento, acabemos eliminando também... a realidade.

Neste contexto difícil e cheio de meandros em constante modificação, como decifrar partes deste ato aparentemente tão simples como parece ser o ato de ensinar, e que ocorre num ambiente especial, a escola (Ramos-deOliveira, 1994) - um local produto da sociedade, mas em relações nem sempre tranqüilas com ela?

Ensinar é exercer atos de comunicação com propósitos definidos. Trata-se de transmitir conhecimentos básicos que formem uma rede de apoios à contínua aquisição e reformulações posteriores. Há nessa construção uma "solidez flexível" ou uma "flexibilidade sólida" - o oxímoro é perfeito para dar conta da originalidade desta estrutura. Os conhecimentos agasalham-se num todo que aceita - e, por vezes, quase que até exige - a modificação de conhecimentos individuais. Um elemento que saia, que seja negado, provoca imediatamente a reorganização do conjunto todo. Novos fundamentos se erguem sobre os antigos e por causa dos antigos existirem ou terem existido. Houve na Grécia Clássica a afirmativa de que "pedras, madeira e barro não fazem uma casa”. Não adianta adicionar mais material, se esses materiais não estão conectados e organizados. Apenas aumentariam a desordem. Assim acontece com o conhecimento.

Um ato de comunicação pode ser uma simples ponte de informações entre pessoas numa espécie de trânsito de mão única ou dupla, mas que não pressupõe a obrigatoriedade de que tais unidades se fixem. Passam, cumprem seu propósito e se apagam. Nós nos comunicamos quando, por exemplo, interrogamos o açougueiro a respeito do preço das carnes que vende e este nos responde. Trata-se de um ato necessário, não resta dúvida, mas esgota-se em si mesmo. Há outros tipos mais fortes de intercâmbio entre pessoas e a educação pressupõe um dos mais importantes: a comunicação real, a troca que enriquece e se fixa não como um elemento estático, mas como um germe, um ponto potencialmente explosivo. Essa é a comunicação educativa, um ato que transforma, modifica, persiste atuante. Bem se vê que esta ação cala, entra, penetra. Tem como uma de suas características o estímulo, o ferrão que estimula respostas imediatas e mediatas. É também resultado de uma expressão, algo que sai de uma pessoa com ênfase e autenticidade. É colorida e densa, profunda e larga. É o verdadeiro ato educativo. É formação. 
Por outro lado, os conhecimentos que realmente significam demandam um trabalho interno considerável. Não são efêmeros nem são rápidos. São "insights", são relâmpagos, mas só se fixam integralmente com a passagem do tempo. Exigem uma sedimentação contínua. Retornam de tempos em tempos, enriquecendo-se e modificando-se. Sem o passar e o decantar do tempo, a formação não se estabelece.

Como assinalou Kant (1985) e como Adorno (1971) reafirmou, a educação tem como "telos" a conquista da autonomia, da emancipação. Esta conquista coloca o aluno numa posição sempre instável, mutável, em que tem que aprender com os outros para compreender a si mesmo e a sua situação, apoiando-se e libertando-se da heteronomia, formulando seu projeto emancipador. Isto demanda trabalho autêntico e reafirma o que mostramos no início desse estudo: a necessidade de conjugar pontas contraditórias, em constante tensão. A adaptação conjugada à transcendência. Uma ação que o obriga a aprender para poder aceitar o que deve ser aceito e a mudar o que pode e deve ser mudado (Burstow, 2000). Sem essas duas pontas, a formação não se consolida. Pelo menos não numa dimensão humana autêntica.

$\mathrm{O}$ ato de ensinar, quando integral, consiste em contribuir à formação do ser, o que se realiza num desvendamento do mundo (como nos é dado pela natureza e pela ação da humanidade ao decorrer dos tempos) que é complexo, que entrelaça o universal e o particular, que é comunicação expressiva e que organiza conhecimentos decantados pelo tempo - e tudo isso como força tensa em busca da emancipação.

Pois é justamente este elenco de características que é afetado ampla e profundamente pelo atual modelo de sociedade em que vivemos. Aos educadores, ou melhor, à escola como um todo, torna-se ato de sobrevivência tomar consciência das linhas gerais que constituem historicamente a sociedade em que vivemos. O exercício do ensino e da educação sem o domínio do pensamento reflexivo pode reduzir-se a uma atividade mecânica destituída do sentido construtor que se busca e que se faz mister alcançar.

$\mathrm{Na}$ atual sociedade, a escola é apenas uma das agências encarregadas da formação dos seres. É especificamente constituída para a formação e, portanto, o local adequado e próprio para uma verdadeira formação. Mas como sua ação autêntica poderia abalar uma sociedade que está construída sobre a desigualdade e que quer e precisa manter a todo custo esta situação injusta, sua ação efetiva encontra a oposição poderosa dos meios de divulgação de massa. Trata-se de um embate desigual em que toda a força parece concentrar-se num dos pólos, justamente no lado contrário à 
verdadeira formação. O enorme poderio dos "mass-media" congrega todos os recursos técnicos da Indústria Cultural e dissemina um sucedâneo da formação, a chamada "semiformação cultural".

Como enfrentar este inimigo todo poderoso e que pelos avanços tecnológicos e técnicos assume mil formas novas a todo momento? Como continuar desconhecendo sua ação, sua presença, sua atração, suas constantes metamorfoses?

O capitalismo sempre teve como traço básico a capacidade de converter em armas todas as oposições que se erguem contra ele. Marx já apontava que o modo de pensar das classes dominantes é o modo de pensar dominante numa determinada formação social. Na verdade, de geração a geração, ou talvez até mais aceleradamente, de tempos em tempos cada vez mais próximos, o modo de pensar e de sentir a existência cotidiana vai se alterando. Comportamentos que encontravam protestos num período vão se instalando e adquirindo garras nos períodos seguintes. Tudo se revoluciona nos movimentos do capital. Tudo se torna simples mercadoria, pronta para consumo, mas destituída de traços realmente significativos. O próprio conceito de Indústria Cultural, instrumento para desvelamento da realidade, pode ser engolido pela própria Indústria Cultural. Basta torná-lo um simples fetiche, um conceito despotencializado. Uma das manobras consiste em aplicá-lo apenas às manifestaçôes mais grosseiras da imprensa falada ou escrita: essas revistas do tipo "romântico vulgar", esses jornais que escorrem sangue a partir das manchetes, essas programaçóes televisivas de exploração dos preconceitos e do chafurdar-se nas superfícies do mundo-cão. Essas aberrações, a bem da verdade, pouca influência exercem sobre o conhecimento e o sentimento do mundo, porque só afetam aqueles que já estão convertidos em pobres párias da cultura. São tão ridículos que "satisfazem" e acabam por enjoar até seus adeptos mais fervorosos. Basta observar com que rapidez tais programas e meios de divulgação de massa são obrigados a se transformarem - no mesmos, com certeza, mas disfarçados com novos nomes e novos personagens. Nascem pelo Ibope e morrem pelo mesmo Ibope. São indústrias, mas dificilmente chegam a ser produtos culturais.

Onde a Indústria Cultural se instala a contento é na faixa atraente das classes médias e superiores - ou seja, a Indústria Cultural se constitui e age a partir... da burguesia. A burguesia não tem o charme que atrai o lumpesinato atual ou o potencial das demais classes? Aqueles ávidos de se travestirem de burgueses, de cultos e dominantes é que se abrem aos mínimos acenos da Indústria Cultural. Esses produtos culturais emanam um encanto, um perfume que embriaga, que seduz. 
A prometida ascensão social ao "self made man" é uma ilusão? Banhemo-nos, portanto, no sucedâneo semicultural. O conhecimento do mundo é uma necessidade ontológica cada vez mais difícil de ser satisfeita? Contentemo-nos com a sucessão de "verdades absolutas" que a toda hora os jornais e revistas, as estações de rádio e de televisão apregoam: canhotos são mais propensos à homossexualidade, descoberta a cura do câncer, o amor pode ser detectado no cérebro, Sadam Hussein é um louco, o mercado mundial atual é o paraíso da livre concorrência, o Estado deve abandonar preocupaçôes e encargos sociais, as loiras são burras, a universidade pública só atende às classes dominantes, o Brasil é abençoado por Deus etc. Que certeza, que tranqüilidade, que paz essa pretensa "ciência de resultados" transmitida pela autoridade dos meios de comunicação de massa dá às populações!

O que é mais perigoso, no entanto, não é exatamente o conteúdo desse bombardeamento de verdades - o mais perigoso é a forma dessa inundação incontida. Por trás dessas mensagens aparentemente inocentes instala-se e se fortalece um conjunto de práticas de pensamento extremamente falsas. Constrói-se uma mitologia moderna. E, como lembramos há pouco, essas práticas vão se fortalecendo como práticas tornadas comportamento habitual, vão se enraizando na nossa maneira de pensar e de sentir, em nossa maneira de ser.

Quando a pequena burguesia se escandaliza, nada corre perigo real. Mas quando a pequena burguesia se entusiasma, se encanta, se entrega a certas práticas, aí então essas práticas se tornam sinais de alerta, perigo! Em todas as civilizaçõos sempre houve a inserção da incerteza e da dúvida, da negação e da contestação - comportamentos altamente benéficos para as constantes correçôes de rota que se fazem necessárias a todo momento da história. O mistério dos oráculos gregos, os koans indecifráveis da civilização nipônica, as lendas e os romanços, as fantasias e os enigmas - a cada contestação ou dúvida a reflexão conquistava novos patamares, readquiria o vetor humano. Mas corremos agora, por via da Indústria Cultural, o grande risco da eliminação dos caminhos alternativos, o enorme abafamento que nos traz a hegemonia crescente do pensamento único. Esse modo de pensar e de ver, de sentir e de concluir é o domínio do pensamento instrumental sobre sua contrafação emancipatória. Instala-se, assim, o modo "McDonaldizado" de pensar - modo que se pretende amplamente majoritário.

Saudar o excesso de informações é ou inocência ou má-fé. Informações desligadas de um contexto real, bombardeadas a todo momento, contraditórias, fragmentadas - o que podem construir? As novas perspectivas trazidas pela Internet são inegáveis, desde que o usuário tenha um centro 
organizador dos conhecimentos que o torne capaz de distinguir o essencial do acidental, o provável do absurdo, o significativo do simplesmente exótico ou até falso. Todo esse progresso tecnológico trazido pelas redes que cobrem o planeta pode ser equivalente a um revólver em mãos irresponsáveis. A tendência ao desgarrar-se do solo existencial e do convívio com seus semelhantes pode trazer frutos perversos. Eis, portanto, um campo todo a ser investigado com responsabilidade e discernimento.

Todo esse conjunto de influências contribui também para a disseminação de uma de-formação a que se dá o nome de semiformação cultural. Em nosso país a semicultura se excede: já conseguiu semiculturalizar inclusive o termo "semiformação cultural"... Um autor, quando queremos realmente conhecer seu pensamento, deve ser lido de preferência em seu próprio idioma. Isto é tanto mais verdade quando estamos lendo um filósofo, alguém que trabalha o raciocínio e a reflexão crítica em seus limites mais amplos. $\mathrm{Na}$ impossibilidade de conhecermos a língua empregada pelo autor, recorremos, então, a traduções confiáveis, ou seja, feitas por quem entende a línguafonte e a língua-destino, além, é claro, de conhecer aquele determinado setor do conhecimento humano. Ocorre que o texto de Theodor W. Adorno que trata da semiformação cultural tornou-se conhecido no Brasil inicialmente por uma tradução espanhola, que adotou a expressão "pseudocultura" - o que significa alterar completamente o conceito cunhado por Adorno. O filósofo da Teoria Crítica emprega o termo alemão "Halbbildung" e Adorno era extremamente rigoroso em sua linguagem. Se quisesse referirse a uma falsa cultura, teria usado algum termo da riquíssima língua germânica que transmitisse esse matiz. O próprio termo grego "pseudo" é amplamente empregado em Alemão: "pseudoepigraphen", "pseudograph", "pseudonym", "pseudowissenschaft" e tantos outros, além de ser também uma língua flexível, com múltiplos recursos de criar termos novos. Portanto, se Adorno recorreu à expressão "Halbbildung" em vez de criar "Pseudobildung" ou "Pseudokultur" é porque estes teriam deformado sua concepção. Não se trata de uma falsa cultura, de uma cultura apenas de aparência ("Anschein"), mas de uma cultura travada, empacada, incapaz de exercer um dos traços básicos da cultura, sua flexibilidade, sua maleabilidade, sua transformabilidade, sua alteração, sua ampliação - enfim, suas inúmeras possibilidades dinâmicas. A semiformação cultural caracteriza-se justamente por seu fechamento, por seu caráter de conclusão: está feita e não admite questionamentos. E cultura que não se renova é cultura que se estiola. Eis o caráter fundamental da semiformação cultural: ela não se autoquestiona, ou seja, não permite o funcionamento da auto-reflexão crítica! Esse tipo de cultura é a morte da cultura em sua dimensão emancipatória, não sua apa- 
rência. Por ser uma cultura às metades, está entorpecida e impede o florescer da cultura de corpo inteiro, a cultura que conjuga e harmoniza as dimensōes instrumentais e emancipatórias num movimento contínuo.

Dissemos até agora dos danos trazidos mais diretamente ao pensamento e aos conhecimentos, embora já tenhamos tangenciado pelas avarias que são trazidas à sensibilidade, mas cumpre desenvolver este fundamental domínio. O processo de amadurecimento, que deveria ocorrer paralelamente ao crescimento da sensibilidade, sói contrapor-se a esta. Não que isto seja um ditame "natural", bem ao contrário: o amadurecimento integral inclui e exige o afinar-se da sensibilidade. Mas se este amadurecimento é feito a duras penas, num processo tortuoso e dolorido, acaba por estancar a sensibilidade para melhor se firmar. O que implica, evidentemente, uma afirmação autocontraditória.

Como a configuração de nossa sociedade num bloco fechado de administração das vidas, dos pensamentos e dos sentimentos de todos nós vai se fortalecendo a cada período sucessivo, acaba-se por endurecer a capacidade de sentir. Uma couraça resistente sente-se contente consigo mesma. Eis, então, outro setor atingido em cheio pela Indústria Cultural: a arte. E com a dimensão artística o que se perde é a capacidade de co-sentir o mundo e o Outro. A procura do sempre igual é uma perda nas tentações narcísicas. Quando rejeito o diferente, quando não tolero o desigual, quando me envolvo em linhas etnocêntricas, então torno-me incapaz de exercer a sensibilidade em abertura ao Outro.

O prazer de criar ou de usufruir obras de arte é traço essencial da dimensão humana. Entorpecer este prazer é, portanto, reduzir as fronteiras que separam a humanidade da barbárie. Quando nos deliciamos (?) com piadas preconceituosas, quando nos encantamos com recursos técnicos vazios de significado, quando nos entregamos às obras que se pretendem artísticas, mas que não passam de divertimento - no sentido original de "verter" em uma contradireção - quando inconscientemente transformamos o "lixo artístico" em objeto de culto - então estão abertas as comportas da barbárie. É uma casca grossa que vai se formando e se consolidando em nossa sensibilidade.

Portanto, a Indústria Cultural e sua contrapartida, a semiformação, constituem-se como as atuais oposiçóes aos esforços de educar. Assim, a escola não pode continuar indiferente a este mecanismo monstruoso que vai, pedaço a pedaço, conquistando as almas.

Mas aquele ato complexo a que nos referimos - o ato de ensinar -, por mais que demande açôes e reaçôes entre o universal e o particular e por 
mais que seja um ato necessariamente orgânico, é, justamente, por tal conjunto de características, detentor de uma qualidade que nenhuma tecnologia ou técnica consegue suplantar. $\mathrm{O}$ ato de ensinar ocorre entre seres e o fato de ser humano, demasiadamente humano, o torna insuplantável.

\title{
TEACHING IN ANADMINISTERED SOCIETY
}

\begin{abstract}
This article uses concepts of the Critical Theory to analyse teaching as an educative act. There is a game of power in continuous tension which characterizes this fundamental human action, one of which is the all-important need to preserve and at the same time to modify. This frame becomes more complex when inserted in our present administered society, which is impregnated by profuse, fragmented and disconnected information. Here is the soil where the culture industry and one of its products - the half-culture - grow. This reflexive conjunct is imperative to every school which intends to be critical.
\end{abstract}

Key words: Culture Industry, Education, Teaching, Administered Society, Instrumental Reason.

Referências bibliográficas

ADORNO, Theodor W. Erziehung zur Mündigkeit, Vorträge und Gespräche mit Hellmut Becker, 1959-1969, edição de Gerd Kadelbach. Frankfurt am Main: Suhrkamp, 1971.

BURSTOW, Bonnie. A filosofia sartreana como fundamento da educação. Trad. de Newton Ramos-de-Oliveira. Educação \& sociedade no 70, ano XXI, abril/2000, p.103-126.

KANT, I. "Resposta à pergunta: Que é Esclarecimento?” Textos Seletos (edição bilíngüe), Petrópolis: Vozes, 1985.

RAMOS-DE-OLIVEIRA, Newton. Tempo dos sofistas, tempo de ruptura? Uma leitura da história a contrapelo. Multiciência no 01, vol. 3, São Carlos, 1998, p. 105-118.

. "A escola, esse mundo estranho". In: Pucci, Bruno (Org.). Teoria crítica e educação: A questão da formação cultural na Escola de Frankfurt. Petrópolis/São Carlos, 1994. 